\title{
Calibration and Uncertainty Analysis for modeling Runoff of the Tambo River Basin, Perú, using Sequential Uncertainty Fitting (SUFI-2) algorithm.
}

\author{
JUAN CARLOS MENDOZA ${ }^{1}$, Sebastian Zuñiga Medina ${ }^{1}$, and Tamar Chavez Alcazar ${ }^{1}$ \\ ${ }^{1}$ Universidad Nacional de San Agustín de Arequipa
}

June 27, 2020

\begin{abstract}
Basin scale simulation is essential to understand the hydrological cycle, specify essential information for water management, for this reason the applicability of the Soil and Water Assessment Tool (SWAT) model is evaluated to simulate runoff in the semiarid basin of the River Tambo (Peru), due to the most economic activities are driven by available water. To achieve the objective of the study, SWAT model was configured using the basin properties such as soil type, digital reduction model, land use, meteorological information such as temperature, temperature of the network of meteorological stations (SENAMHI). The SWAT model was calibrated using the SUFI-2 algorithm for the periods from 1994 to 2001, with 3 years of warming and validated from 2002 to 2016 using daily river discharges. The results during the daily and monthly calibration period had Nash-Sutcliffe Simulation Efficiency (NSE) of 0.69 and 0.86, Determination Coefficient (R2) of 0.70 and 0.87 , Percent bias (PBIAS) of -14.4 and Ratio of standard deviation of the observation of the root mean square error (RSR) of the root of 0.55 and 0.37 , respectively. For the daily and monthly validation period, they had NSE of 0.52 and 0.70, R2 of 0.67 and 0.87 , PBIAS of -6.1 and RSR of 0.69 and 0.55 , respectively. These results indicate that the SWAT model has the ability to predict current flows within the river basin of the Tambo Valley in southern Peru, being a useful tool for a more detailed analysis of the effects of climate change, change of land use, water quality analysis and sediment performance analysis.
\end{abstract}

\section{Hosted file}

MainDocument .pdf available at https://authorea.com/users/337438/articles/463039-calibrationand-uncertainty-analysis-for-modeling-runoff-of-the-tambo-river-basin-per\%C3\%BA-usingsequential-uncertainty-fitting-sufi-2-algorithm 

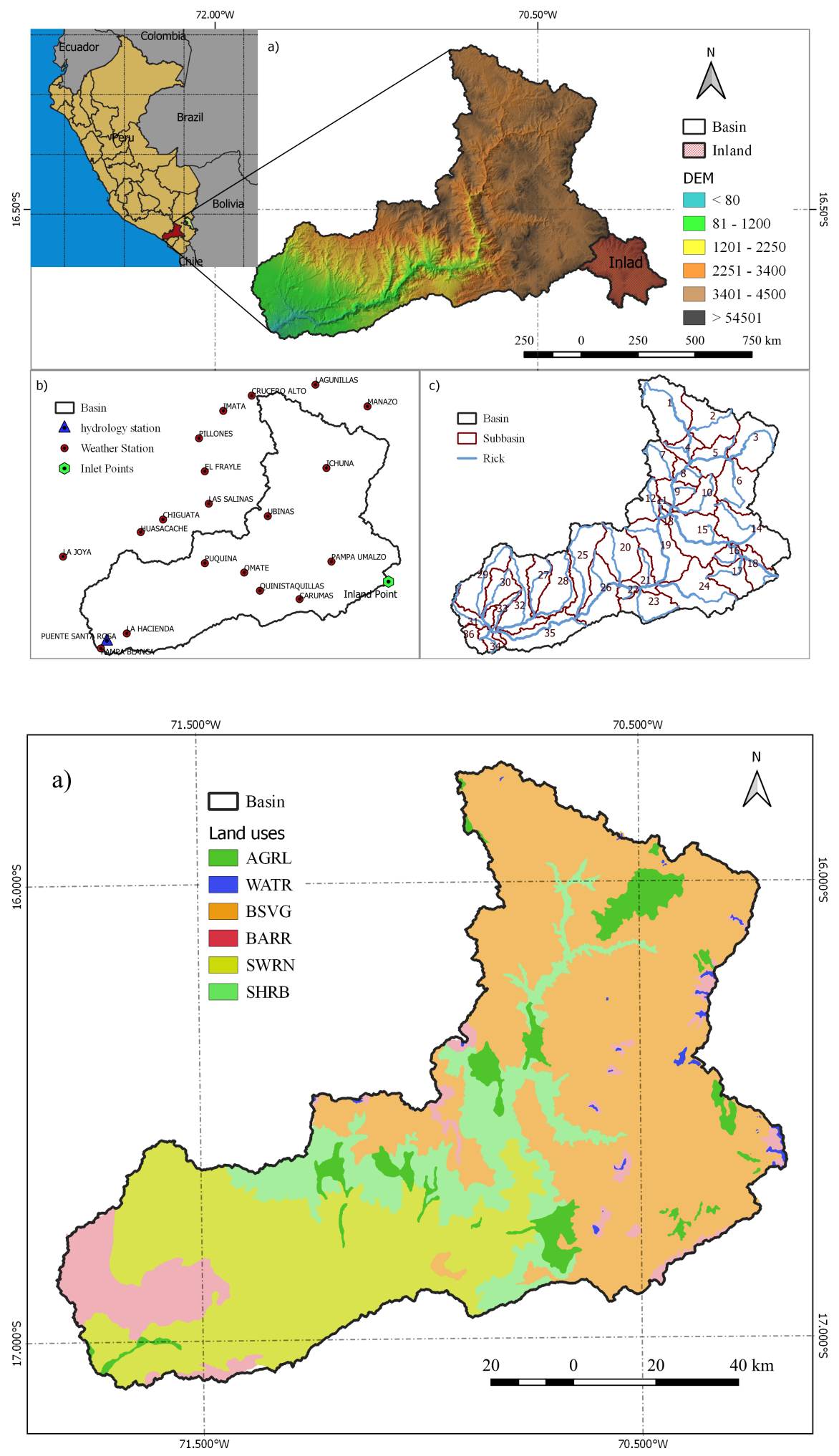

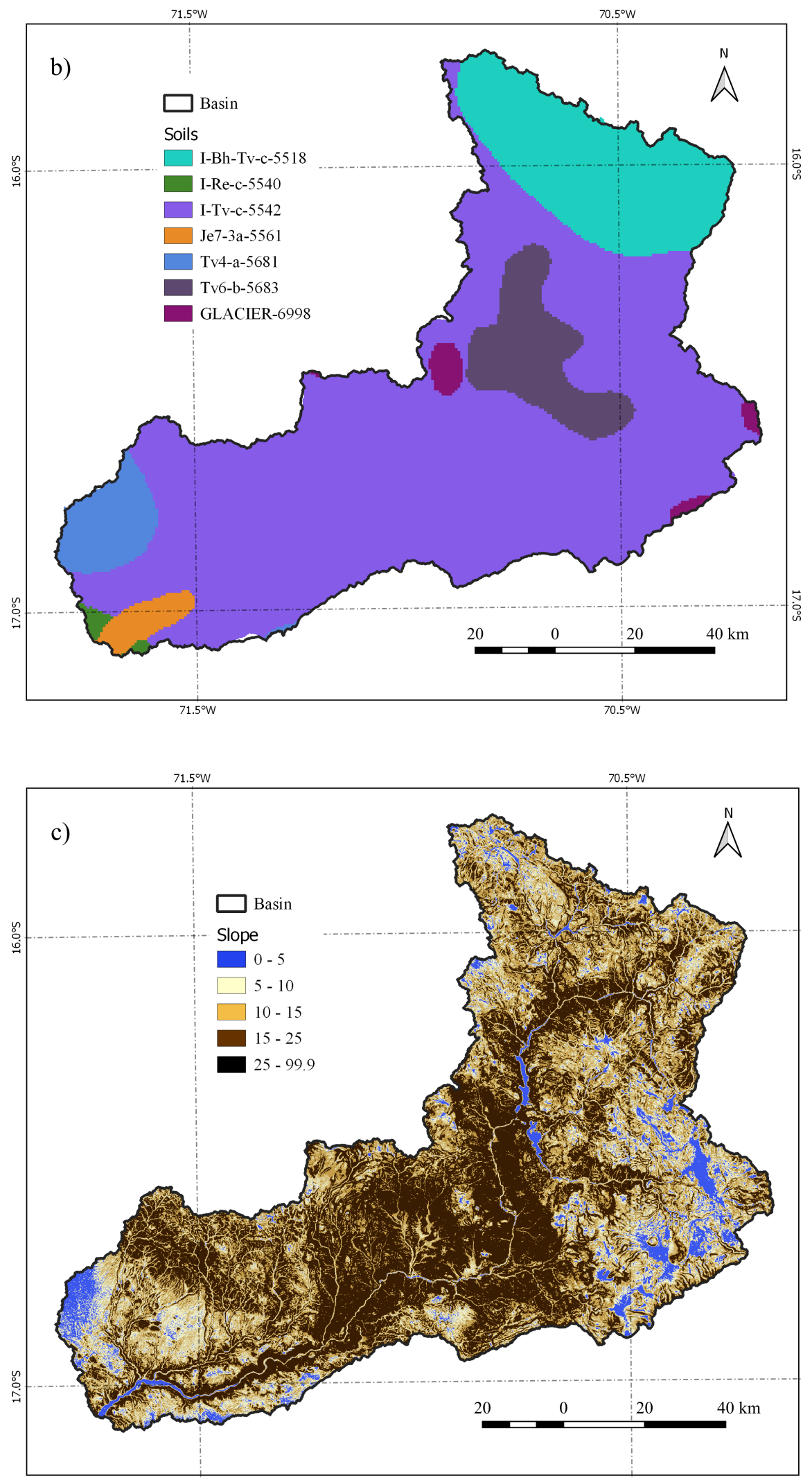

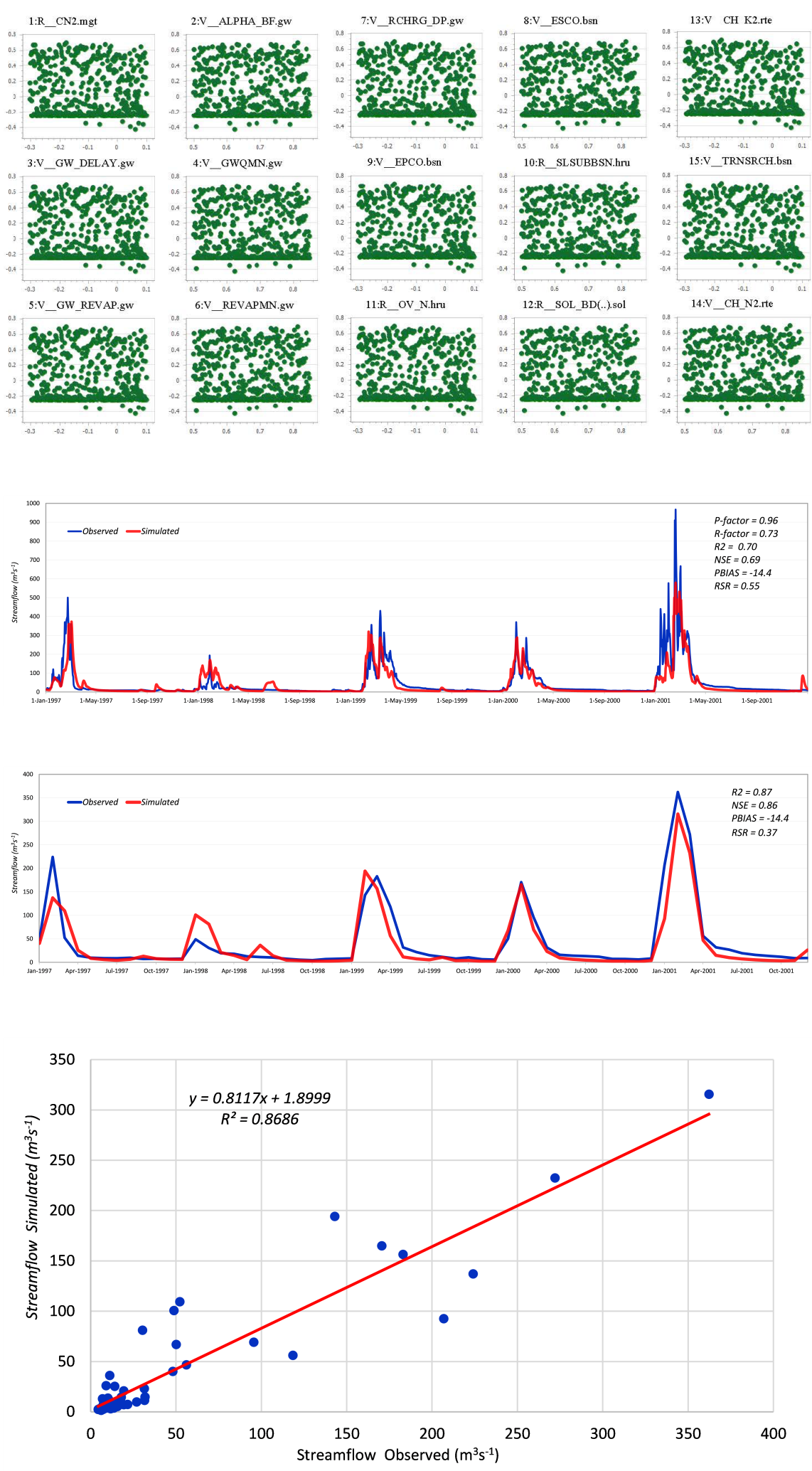

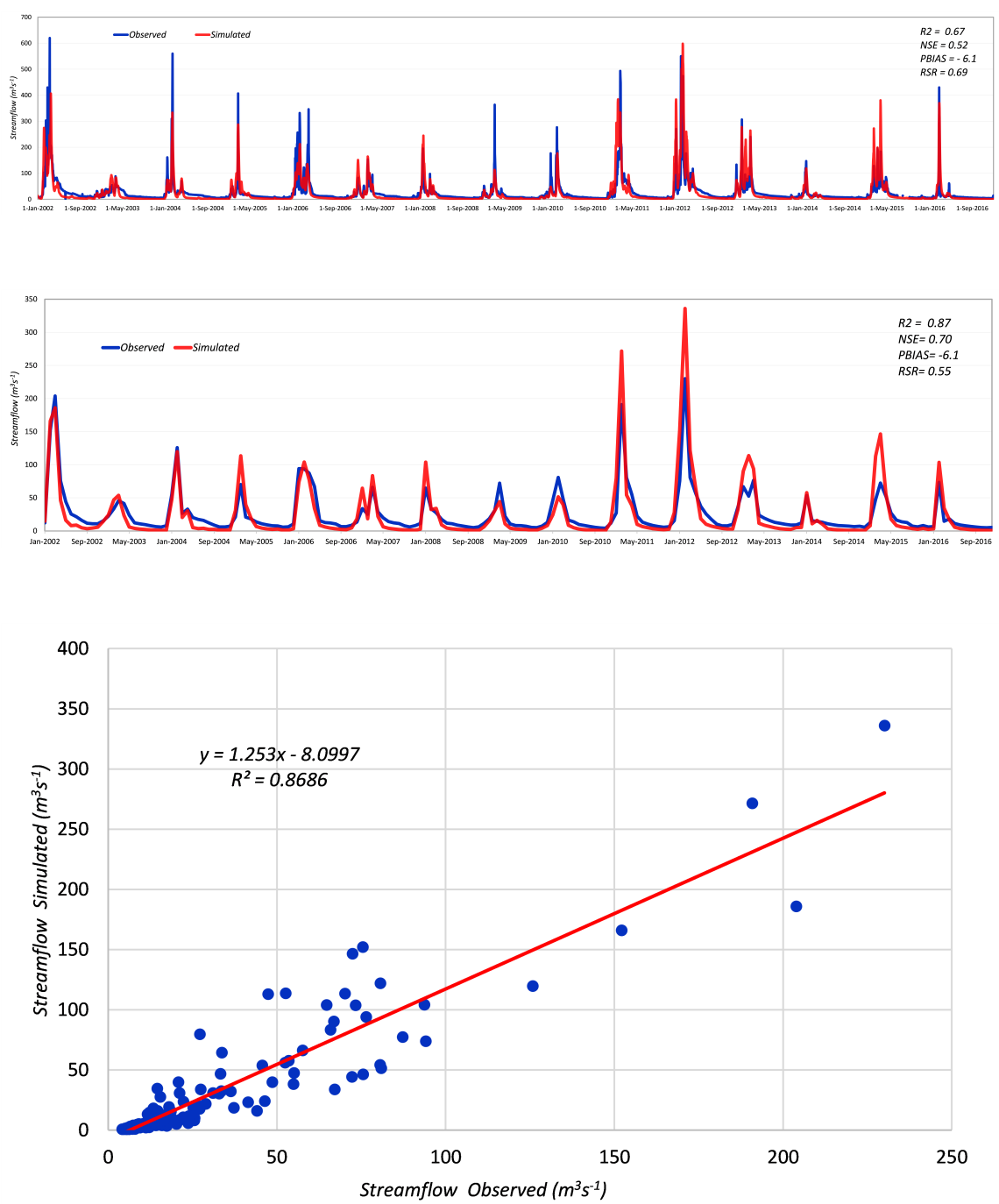